\title{
Program Evaluation and Review: Online Training for Apprenticeship Trades
}

\author{
Rosemary Vogt \\ Red River College, Canda
}

\begin{abstract}
Due to the alleged skill shortage across Canada, Red River College in Winnipeg partnered with Apprenticeship Manitoba for the purpose of designing, developing and delivering an alternate model of program delivery for apprenticeship education comprised of distributed learning using hybrid or blended learning methodology. This case study identifies the experiences and recommendations of individuals associated with the project. This case study is significant as the literature is void of empirical data relating to any model of training delivery for apprenticeship training in Canada or elsewhere.
\end{abstract}

\section{Introduction}

In many trades, the demand for training seats has strained the conventional delivery capacity of training providers with respect to meeting the needs of the Manitoba labour market. In 2008, Red River College investigated ways to expand capacity for apprenticeship training, which resulted in recommendations to develop an alternate model of program delivery comprised of distributed learning using hybrid or blended learning methodology. In the fall of 2009, Red River College partnered with Apprenticeship Manitoba to design, develop and implement online training for selected apprenticeship trades. The intention was to provide an alternative to traditional block release training (typically 8-10 weeks) by increasing access to training for a wider demographic. Known as the E-Apprenticeship Alternative Delivery Development Initiative (EADDI), this model provides community-based training and reduces the amount of time apprentices need to leave their community to complete their level training at one of Manitoba's technical colleges.

\section{Research Background}

The Conference Board of Canada has identified a skills shortage across Canada with implications that pose a serious threat to the competitiveness of Canadian industries and participation in the knowledge economy (Conference Board of Canada,
2013). Therefore, it is important that leaders in higher education understand the link between international competitiveness, post-secondary education and a skilled labor force (Partnership for $21^{\text {st }}$ Century Skills; The Council of the Federation; Committee for Economic Development, 2013). Industry Canada perceives that the speed of adjustment in market requirements for skilled labour depends on how the post-secondary education system responds to the volume and type of skills required (Government of Canada). Predicting future skill requirements and job markets is challenging due to the tenuous nature of the labour market information used to forecast approaching demographic changes.

Given these considerations, the objectives of this case study are to examine an online training delivery model for apprenticeship technical training, specifically EADDI. The case study is significant as the literature is void of empirical data relating to any model of training delivery for apprenticeship training in Canada or elsewhere. Therefore, the data does not link to any other findings or research on apprenticeship training programs. This groundbreaking data is important for future researchers and subsequent inquiry on alternate models of program delivery for apprenticeship education.

\subsection{Delivery Objectives}

The program delivery model for EADDI was generated based on a distributed cohort model in which apprentices work through online modules individually and meet in a virtual classroom twice a week to discuss their learning. As in traditional faceto-face delivery, the EADDI delivery model requires apprentices to engage in individual and group learning activities. Where appropriate, apprentices engage in small workplace projects to enhance their learning. Apprentices meet face-to-face on two occasions: (1) for an orientation at the beginning of their level training to learn the skills necessary to be online learners, and (2) at the end of their program for a Capstone ${ }^{1}$ to refine and demonstrate their

\footnotetext{
${ }^{1}$ A period of time (typically 1 week in duration) when
} 
practical skills. In some trades, apprentices also write qualifying examinations for their level of training during the Capstone period.

\subsection{Benefits and Key Features of EADDI}

There are numerous benefits and key features of the EADDI model of program delivery. EADDI eliminates the need for apprentices to go on Employment Insurance while completing level training and reduces employers' loss of staff. It enables communities to retain their people since apprentices frequently fill multiple roles in their community such as coaches for local sports teams and volunteer firefighters in addition to being spouses and parents. The EADDI model also offers the potential for reduced cost delivery. Discussions are currently underway regarding modularizing the online content to serve as a resource for face-to-face instruction, for remediation as well as for supporting the provincial bridging program for foreign-trained trades professionals.

\subsection{Fundamental Conditions for EADDI}

There are five fundamental conditions for EADDI to be successful:

1) The training delivery model needs to fit realistically within commitments of apprentices' employment, family and community.

2) The apprentice remains in the community working full-time with the exception of attending a face-to-face orientation session at the beginning of program delivery and attending the Capstone at program completion.

3) The level training must be delivered to the same standards as the traditional block release oncampus model.

4) The level must be deliverable within a reasonable time span, preferably in non-peak seasons.

\subsection{Development and Delivery}

During the initial stages of content development for EADDI, it was anticipated that an alternative level of electrical would span approximately six months from October to May with a two week break over the winter holidays. It was expected that apprentices would spend approximately 22 weeks online in addition to ten days on campus for a total of $300^{2}$ hours of instruction. A ten-hour weekly cycle was projected on a four-hour employer release during a workday plus six hours

apprentices demonstrate the hands-on, practical components of their level training in a face-to-face learning environment.

${ }^{2}$ Number of hours varies based on trade requirements. to be scheduled in two-hour blocks by the apprentice according to the needs of the curriculum.

Although EADDI was anticipated to provide distributed learning for apprentices in their own homes, in November 2012, Levels 1 and 2 of the Electrical program rolled out to two cohorts of apprentices employed with Manitoba Hydro in Gillam, Manitoba. ${ }^{3}$ Both cohorts met at the Radisson Converter Station twice a week to participate in a virtual class environment using Blackboard Collaborate ${ }^{4}$ in addition to completing online independent study. There were seven apprentices in each level. One apprentice in Level 2 participated from an offsite location in western Manitoba. In June 2013, both levels of apprentices successfully completed their level training. The Level I cohort completed the Capstone requirement onsite in Gillam, while the Level 2 cohort completed the Capstone at Red River College in Winnipeg.

\section{The Purpose of the Study}

There is a noticeable absence of formally documented data or research to support the experiences of individuals invested in developing and implementing an alternative delivery model for apprenticeship trades technical training. The primary purpose of the 2013 study was to document the experiences and feedback of apprentices, apprentice supervisors, instructional designers, instructional design technicians, subject matter experts (SME's), online instructors, department coordinators, Chairs, EADDI program manager and administrator. The experiences of individuals who fill these rolls has been collected and analyzed in this study.

The secondary purpose for conducting this research was to examine the need for continuous improvement purposes for subsequent EADDI development and delivery. The report supports the request for EADDI program evaluation as called for in the Request for Proposal (2008). The role of empirical research in collecting data and using that data to initiate dialogue and action in educational forums is an advantage for all stakeholders.

\subsection{Evaluating Programs}

Institutions of higher education are faced with competing internal and external demands that intimidate the capacity to meet increasing expectations for diverse program delivery [5]. These

\footnotetext{
${ }^{3}$ Gillam is situated 1,062 kilometers north of Winnipeg between Thompson and Churchill.

${ }^{4}$ Blackboard Collaborate is an online collaboration platform providing web conferencing, mobile collaboration, instant messaging and voice authoring.
} 
demands have been recognized in Manitoba where the status quo for apprenticeship program delivery is no longer acceptable due to the increased market demand for skilled labor in the province. The increased demand for skilled labor delivers a clear and compelling message identifying the need to reform models of program delivery. A program being "any activity or collection of activities . . that consumes resources (dollars, people, space, equipment, time)" [5]. Program evaluation and review involves an examination of the program's strengths and weaknesses and is generally used for program improvement. There should be a concentration on resource development and utilization as well as focus on elements that address efficiency, effectiveness and centrality to institutional mission. There should also be a logical basis for identifying opportunities to "increase revenue, reduce costs, improve quality, and strengthen reputation" [5].

\subsection{Research Questions and Method}

This program evaluation and review case study posed the following questions:

1. Who has participated in the EADDI program? What are participant's roles?

2. What prior experiences with alternative delivery models did EADDI program participants already have?

3. What are the experiences of participants in the EADDI program?

4. What were participant's views on the strengths and weaknesses of the alternative delivery model?

5. What recommendations do EADDI program participants have for subsequent development and delivery of alternative delivery technical training?

In depth individual face-to-face interviews were conducted over a period of six weeks from June 5 to July 2, 2013. With the exception of one apprentice, the one-on-one interviews with apprentices and apprentice supervisors took place at the Manitoba Hydro Radisson Converter Station near Gillam Manitoba. Instructional designers, instructional design technicians, subject matter experts, online instructors, department coordinators, Chairs, EADDI program manager and administrator were interviewed at Red River College in Winnipeg Manitoba. Twenty-eight people in total participated in the one-on-one face-to-face interviews. The rational for this selection of participants being that each interviewee was directly situated in a role related to the feedback required by the Apprenticeship Manitoba Request for Proposal
(2008). The interview data from each of the informants was transcribed verbatim and analyzed for common themes; the themes are represented in the findings.

\subsection{Significance of the Study}

This study is significance due to the current scarcity of Canadian research on alternative delivery models, specifically for apprenticeship trades. Three key points suggest the importance of the topic for this study: (i) The field of research lacks a coherent body of data on alternative delivery models, (ii) Researchers are probing questions about how to plan, design and implement meaningful learning experiences for online learners, (iii) What happens when you blend traditional face-to-face instruction with self-directed online learning and a virtual classroom experience for apprenticeship trades? Responses to questions regarding participant experiences with the EADDI delivery model may inform the design and development of subsequent models of alternative delivery. The benefit of more informed alternative delivery models is improved learner engagement.

\section{The Literature Review}

Currently researchers are asking probing questions about how to plan, design and implement meaningful learning experiences for online learners. Analysts have frequently focused on the usefulness of case studies for comparative analysis and making meaningful decisions about e-learning practices. A reoccurring theme in the literature indicates that effective practice criteria need to be developed. As technology is changing the service delivery options available to learners, course and program developers are eager to understand how to best meet the needs of online learners. Currently there is no pedagogical model for online learning that developers can apply to all aspects of designing, developing and implementing online learning alternatives. A continuous dialogue about the development process is required [1].

\subsection{A Review of Literature from 1996-2008}

A report by Means, Toyama, Murphy, Bakia and Jones provides a comprehensive review of e-learning literature from 1996 - 2008 using over a thousand empirical studies [8]. The Meta analysis combining results from multiple experiments found that on average students in online learning environments performed modestly better than those receiving the same instruction in face-to-face environments. The results were attributed to blended conditions where learners received additional learning time and 
instructional elements not received by students in face-to-face environments. The findings suggested that the "positive effect associated with blended learning should not be attributed to media" (p. ix), rather the incorporation of mechanisms that promote student interaction, reflection and level of understanding [1].

\subsection{Ensuring Success}

Folinsbee seeks to answer questions about how to ensure online learning alternatives are effective and successful [6]. The author reviewed key documents from the last eight years noting, "Online instructors need advanced technological skills, more patience than the traditional classroom [instructor] and the ability to develop confidence and comfort with students" (p. 10). The findings emphasize the need for patience and "experimentation to determine what works ... and training and support for both faculty and students" (p. 18).

\subsection{A Gap in the Literature}

Research on online learning in Canada has not been a priority; there is almost no research on hybrid courses or design (Contact North). Therefore, collecting data on the development of new models for online delivery deserves attention. Questions abound about what happens when service providers combine traditional face-to-face instruction with selfguided online learning and virtual classroom technology. As educational service providers increasingly compete for student enrollment and students explore online learning options more empirical research is required to inform the development of learning experiences to engage learners.

\section{Methodology}

This case study focuses on the experiences and recommendations of individuals associated with designing, developing and delivering an alternative model of program delivery for apprenticeship trades using an online hybrid blended approach. Qualitative research methodology was chosen as it lends itself to the use of in-depth participant interviews using open ended questions to elicit as many details as possible from the informant; participants can answer from their own frame of reference, freely expressing their thoughts and feelings. Qualitative research methodology seems to be an appropriate method of inquiry for documenting the experiences and recommendations of individuals associated with designing, developing and delivering an alternate model of program delivery for apprenticeship trades technical training. These individuals include apprentices, apprentice supervisors, instructional designers, instructional design technicians, subject matter experts (SME's), online instructors, department coordinators and project managers. The collection of the data occurred through audio recorded one-on-one face-to-face interviews with participants in May and June of 2013 at Red River College in Winnipeg Manitoba and with Levels I and II Electrical apprentices at the Radisson Hydro Generating Station in Gillam Manitoba.

\subsection{Participant Recruitment and Participation}

The recruitment of participants occurred following approval from Red River College Research Ethics Board. Once approval had been granted, participants were invited through an e-mail which articulated the purpose of the study and the research questions. The invitation for participation clearly identified that participation in the study was voluntary; it detailed the time commitment required for participation and ensured anonymity.

All of the apprentices who participated in the interviews for this study were unfamiliar to the primary researcher; there were ten male and two female. Of the seven supervisors in Gillam Manitoba, six were unfamiliar to the primary researcher. The seventh supervisor had been instrumental in assisting the primary researcher with making arrangements for the Gillam interviews. The remainder of the participants (seven) were all known to the primary researcher; the total number of participants numbering 28 .

\subsection{Researcher's Position in the Study}

Every researcher has their own biases and it is important that these biases be recognized at the onset of a research project. Creswell believed the researcher must attempt to reduce the influence of any prejudgments and past experiences [3]. It is the researcher's responsibility to remain neutral and unbiased during the data collection process and analysis [7]. Prior to the commencement of the participant interviews for this study in June 2013, all participants were informed of the primary researcher's position in the study and history with EADDI in an endeavor to promote disclosure and transparency in the research.

\section{Findings}

Project managers stressed the importance of institutional communication from senior levels of administration regarding the launch of a new model of program design, development and delivery. The importance of institutional ownership and buy-in 
from all stakeholders simply cannot be overstated. Designing, developing and delivering an online alternative model of program delivery for apprenticeship training requires consideration regarding the diversity inherent in each trade and at every level within a trade. Consideration must be given the availability of committed and sustained subject matter expert (SME) time. It should also be anticipated that SME's attitudes will vary in terms of commitment to a project development initiative which in turn results in considerable pressure on the instructional designer who is responsible for adapting apprenticeship curriculum into an online format.

Instructional designers and technicians reported working with subject matter experts to develop course content as the most challenging aspect of program development due to SME (un)availability and tight deadlines. Major weaknesses in the design, development and delivery of the EADDI initiative were identified as inadequate communication between stakeholders, a one-size-fits-all approach with regards to course look and feel and an overextended commitment to produce an alternate model of program delivery within an unrealistic time frame. Instructional designers and technicians recommend a flexible approach to developing alternative programming, constant re-evaluation of the processes and enhanced communication between stakeholders.

While subject matter experts recognised the potential of the EADDI model to provide technical training to apprentices for whom attending face-toface instructional classes at a technical college is a hardship, they generally remained dubious due to the tacit historical nature of learning an apprenticeable trade through a blended online model. Likewise, instructors were skeptical about the concept of online learning and the robustness of the level training curriculum. Instructors reported feeling unprepared for delivering instruction online even though some training had been provided prior to delivery. Unanswered questions and insecurities prevailed concerning how to use the document camera in virtual environment and how to give students access to voice and chat.

Program coordinators and chairs reported that releasing instructors from regularly scheduled faceto-face instructional responsibilities for the purpose of creating and delivering programming for EADDI was the primary challenge associated with the project. Also reported was a significant stigma surrounding the EADDI model, as many instructors did not believe that technical training for apprenticeship trades could be delivered online.

Apprentices reported previous experience with online learning as beneficial, however, not essential; apprentices with families reported difficulty in finding a quiet space for study. Appreciation for recorded sessions on the Live virtual classroom platform and camera use by instructors was favorably noted. Nearly unanimously, apprentices agreed that the EADDI model suited their needs as an apprentice in a remote northern region. Although several of the apprentices stated they would prefer to take their level training down south citing the social benefits of being on a campus in a large city. Weakness of the blended or hybrid delivery model centered on the duration of the level training (30 weeks), as well as inadequately prepared and indifferent attitudes of instructors.

Apprentice supervisors at Manitoba Hydro reported overall satisfaction with the alternate model of program delivery although they would like to see a more condensed delivery model (10-12 weeks). Some glitches were noted attributed to instructor unfamiliarity with using technology and inconsistent use of recorded sessions and web camera. Apprentice marks were noted as being as good as or better than apprentices attending face-to-face program delivery at one of Manitoba's technical colleges. Supervisors unanimously agreed that the best feature of the EADDI model was the opportunity for apprentices to remain in their community where they are entrenched in family responsibilities and various volunteer roles in the community.

\section{Limitations of the Study}

The small number of instructional designers (2), instructional design technicians (1), subject matter experts (1), department coordinators (1), and department Chairs (1) present potential limitations to this research study and EADDI report. A larger number of interview participants occupying these roles may result in a more in-depth representation of experiences. Moreover, the EADDI program was designed with cohorts of widely distributed apprentices in mind. With the exception of one apprentice attending remotely from Brandon, the two cohorts who participated in this study were situated in a classroom context at the Radisson Converter Station near Gillam Manitoba. A larger cohort of widely distributed apprentices may result in a more in-depth representation of apprentice experiences with the EADDI model of program delivery.

\subsection{Implications for Practice}

The optimal mix (combination of self-guided learning, virtual classroom training and face-to-face instruction) in alternate delivery technical training is a moving target. The mix that was created for the Gillam project with an expected 10 hour a week commitment from the apprentices split up into six hours of Elluminate Live training with the instructor and four hours of online independent learning 
coupled with a Capstone at the end is a mix. The optimal mix of an alternative delivery model depends on the trade to some extent. Some trades lend themselves well to the online distance cohort and others do not. The optimal mix seems to be something that allows people to work the learning in with their regular schedule and commitments. The learning blocks are quite short, no more than two hours at a maximum; perhaps even an hour is ideal. Entire programs do not lend themselves well to total online delivery. However, there are certain units within any level of programming that can be done online and you should be able to deliver an entire level within a larger program.

\subsection{Best Practices for Innovation in Alternate Model Program Delivery}

Best practices for alternate models of program delivery vary by program, trade or unit. The EADDI model of online alternative delivery endeavoured to mimic what learners experience in a face-to-face program at Red River College. However, assuming that learners are recipients of best practices in a faceto-face program at the college may be a false assumption. Best practice means frequent assessment to confirm that the learner is aware of their progress at every cycle in the learning. Best practice means that the learner is able to operate at a maximum level of self-sufficiency through the provision of learning supports. You cannot assume something is a best practice based on one experience. It requires numerous experiences to determine what best practices are and what is most effective.

\subsection{Screening and Selection of Clients for EADDI}

Experience with the EADDI project confirmed what the EADDI team already knew about online learning for apprenticeship trades: e-apprenticeship is not for everybody. Online learning requires a certain level of skills and dedication that are not typical. The entry into e-apprenticeship is in many ways a self-serve process; people have to self-enroll. Precisely how apprentices enroll in the program has a great deal to do with who they work for. EADDI is not responsible for recruiting the apprentices and does not have information about the screening and selection of clients. The SmarterMeasure assessment tool was recommended to Apprenticeship Manitoba for the purpose of gauging whether an individual is ready to learn online. SmarterMeasure is a good screening tool. It tests certain skills and demonstrates what it is like to sit in front of a screen, concentrate and get organized for computer based instruction.

\subsection{Design Considerations and Final Targeted Length of Technical Training}

It is still too premature to identify the final targeted length of technical training for EADDI. A level of training is anywhere between 280 and 340 hours of instruction. How those hours get reflected into training time when an apprentice is working is a challenge. A level of training takes approximately ten hours a week to complete. For a 300 hour level that would be 30 weeks of time. That is the outside limit of what someone can do and maintain their commitments in the community. This formula evolved into an ideal which became known as the 10-4 model. The 10-4 model proposed 10 hours a week of study with four hours of release time from the employer; the apprentice was responsible for accommodating the remaining six hours. The only way EADDI could get 300 hours of instruction within a reasonable period of time from October to June was to have a model where the employer gave a half day a week to make it happen. For an employer like hydro this is a workable model as they have large numbers of trainees and control their schedule. This model has not worked well for small employers who would rather send their apprentice to Winnipeg for ten straight weeks as opposed to giving them a half-day a week for 20 or 30 weeks.

\subsection{Development and Production Considerations}

The most important development consideration for the EADDI project has been getting committed and sustained subject matter expert time. When the project began it was anticipated that it would be possible to contract with departments to get six, ten or twelve week blocks of instructor time dedicated to content development for EADDI; that did not happen. This can be attributed to departments who are already tightly scheduled and do not have available instructors to work on additional projects. Due to the difficulty in obtaining subject matter experts progress suffered from the start. Once secured to work on the project it became evident that subject matter experts varied greatly in their commitment to the project. Some of them had the skills, aptitude and enthusiasm for developing course material for online learning while others did not. This created a lot of pressure for instructional designers who worked within tight deadlines and suffered from not knowing the subject content. The most predominant delivery consideration was training subject matter expert instructors to teach online. Instructors who taught online went through a very steep learning curve adapting their teaching instincts to an online environment. A gap in the promotion of EADDI to potential clients was another 
delivery consideration. The EADDI model of content delivery for apprenticeship trades has not been promoted; consequently a lot of questions remain unanswered.

\subsection{Strengths and Weaknesses of Project Design}

Strength: The primary strength of EADDI has been creating content delivery for a whole level of apprenticeship training at a time as opposed to little bits and pieces here and there.

Nearly unanimously apprentices agreed that EADDI was "Gillam appropriate" with the best feature of the EADDI model being the ability to remain at home with family and in community as opposed to spending ten weeks down south paying rent. When emergencies arose and an apprentice needed to remain at home or at the hospital to care for a sick family member, EADDI presented the opportunity to $\log$ into the virtual classroom remotely. Additional strengths were cited as the benefit of the cohort model and classroom environment, cohort unity and instructor support.

Weaknesses: The missed opportunity to be seen as a major initiative has been seen as a primary weakness in the project design. Although the project was approved through various stakeholders it struggled to become recognized as an institutional project. Consequently, it appeared as though the project was initiated through specific individuals in the college Teaching Learning and Technology Center who had decided to put some apprenticeship training courses online and were troubling the departments to get people to help out. It took a long time for the college to negotiate its formal contract for the project and this may have attributed to the prevailing absence of organizational awareness and understanding of EADDI; college wide pride in the EADDI project failed to materialize. It remains uncertain whether the EADDI project as an institutional project was ever communicated through a stakeholder communication plan: little evidence of that has been recognized. It was unforeseen that something that was generating a million dollars a year of activity did not attain greater prominence within the college community.

At the onset of EADDI costing for subject matter experts (SME's) was projected based on one or two SME's being responsible for an entire level of training. As work on the project progressed, it was determined that each level of training required at least three and often as many as six or more SME's. Consequently, there were challenges securing SME time from departments. Securing SME's from departments also created further challenges as instructors could not easily be released from face-toface instructional duties and backfilled. Frequently when SME's became available it did not align with instructional designer availability.

EADDI made numerous erroneous assumptions about the availability of SME's. When the project first rolled out it was identified that a certain number of courses and levels would be developed within a specific period of time and that it would require an identified number of SME's to deliver the content. Program completion projections were made on mistaken assumptions regarding availability of SME's. During very early stages of EADDI content development it became evident that departments were strapped for instructors. Frequently when SME's were released from face-to-face instructional duties for a period of time to develop EADDI content, an absence of SME buy-in was observed.

There was a false assumption made on the part of stakeholders that it would take the same length of time to create a whole level of training as it took to create one course within a level of training. When courses are developed for other programs like Continuing and Distance Education (C\&DE) it takes about four months to develop a course. Therefore it was estimated that an entire level of apprenticeship training would take about four or five months to develop. What was not taken into account was that a course for C\&DE or any other department is 32 credit hours and Level 2 Electrical, for example is 350 credit hours; that is 10 times longer. Yet, the expectation was that EADDI would develop the whole level in six months. That was a flaw in logic.

\section{Recommendations}

The research data from this case study has resulted in the following recommendations:

1. Duration: A modification to program duration needs to be negotiated for a Manitoba Hydro cohort (or any other client).

2. More polished program delivery: Action must be taken to ensure all online instructors receive adequate initial training and on-going support. Given that instructors faced challenges due to inexperience with learning technologies during program delivery and these insufficiencies impeded apprentices' learning experiences, instructor training and ongoing support with regards to program delivery must be a priority.

3. A flexible approach to developing alternate program delivery: Subsequent initiatives must embrace a flexible approach to program design, development and delivery recognizing that a one size fits all approach is not suitable for apprenticeship trades technical training.

4. Subject Matter Experts: A more proactive approach needs to be adopted in order to avoid 
the subject matter expert pitfalls experienced in the past.

5. Communication: There must be improved communication between all internal and external stakeholders.

\section{Conclusion}

This case study has examined the EApprenticeship Alternate Delivery Development Initiative (EADDI), a collaborate project between Red River College and Apprenticeship Manitoba. Evidently, there were many individuals with diverse roles directly or indirectly associated with EADDI. It is also evident that the project could be improved with the adoption of a communication plan and various amendments for subsequent design, development and delivery. As EADDI moves forward into a second phase of development, lessons learned inform avoiding the previously experienced pitfalls. Finally, the data informs the possibilities for enhancing apprentice access to technical training in the effort to provide more skilled labour which in turn increases the competitiveness of Canadian industries and participation in the knowledge economy.

\section{References}

[1] Beetham, H., (2005). E-learning research: Emerging issues Research in Learning and Technology, 13(1), pp. 81-89.

[2] Bennett, S. K., Maton \& L. Kervin, (2008). The digital natives debate: A critical review of the evidence. British Journal of Educational Technology. 39(5), 775-786.
[3] Creswell, J. W., (2009). Research design: Qualitative, quantitative, and mixed methods approaches. (3rd ed.). London: Sage.

[4] Contact North, (2012). Toward an online learning research agenda for Ontario: Themes, opportunities and challenges. Ontario Distance Education Trainin Network. Retrieved from www.contactnorth.ca.

[5] Dickeson, R. C., (2010). Prioritizing academic programs and services: Reallocating resources to achieve strategic balance. San Francisco, CA: Jossey-Bass.

[6] Folinsbee, S. (2008). Online learning for adults: Factors that contribute to success. College Sector Committee for Adult Upgrading. Retrieved from http://www.collegeupgradingon.ca/ace/litreview/litreview. pdf.

[7] Kirby, S. L., Greaves, L., \& Reid, C., (2007). Experience research social change. Peterborough, ON: Broadview Press.

[8] Means, B., Yoyama, Y., Murphy, R., Bakia, M., and Jones, K. (2010). Evaluation of evidence-based practices in online learning: A meta analysis and review of online learning studies. $U . S$. Department of Education Office of Planning Evaluation, and Policy Development Policy and Program Studies Service.http://www2.ed.gov/rschstat/eval/tech/ evidence-based-practices/finalreport.pdf 